\title{
Am-U (Americium-Uranium)
}

\section{H. Okamoto}

The Am-U phase diagram was calculated by [1993Oga] using a regular solution model (see [1999Oka]). The phase diagram was incomplete, as low-temperature allotropes of both terminal elements were not taken into account.

Figure 1 shows a complete Am-U phase diagram calculated by [2010Kur] based on the thermodynamic database created consistently for actinide elements.

Table 1 shows Am-U crystal structure data. The approximate composition range for each phase was read from the phase diagram

\section{References}

1993Oga: T. Ogawa, Alloying Behaviour Among U, Np, Pu, and Am Predicted with the Brewer Bond Model, J. Alloys Compd., 1993, 194(1), p 1-7

19990ka: H. Okamoto, Am-U (Americium-Uranium), J. Phase Equilib., 1999, 20(4), p 452

2010Kur: K. Kurata, Thermodynamic Database on U-Pu-Zr-NpAm-Fe Alloy System II-Evaluation of $\mathrm{Np}$, Am, and $\mathrm{Fe}$ Containing Systems, IOP Conference Series: Mater. Sci. Eng., 2010, 9, 12023, 8 pp

Table 1 Am-U crystal structure data

\begin{tabular}{|c|c|c|c|c|c|}
\hline Phase & Composition, at.\% U & Pearson symbol & Space group & Strukturbericht designation & Prototype \\
\hline$(\gamma \mathrm{Am})$ & 0 to 1.5 & $c I 2$ & $\operatorname{Im} \overline{3} m$ & $A 2$ & $\mathrm{~W}$ \\
\hline$(\beta \mathrm{Am})$ & 0 & $c F 4$ & $F m \overline{3} m$ & $A 1$ & $\mathrm{Cu}$ \\
\hline$(\alpha \mathrm{Am})$ & 0 & $h P 4$ & $P 6_{3} / m m c$ & $A 3^{\prime}$ & $\alpha \mathrm{La}$ \\
\hline$(\gamma \mathrm{U})$ & 98 to 100 & $c / 2$ & $\operatorname{Im} \overline{3} m$ & $A 2$ & $\mathrm{~W}$ \\
\hline$(\beta U)$ & 100 & $t P 30$ & $P 4_{2} / m n m$ & $A_{b}$ & $\beta U$ \\
\hline$(\alpha U)$ & 100 & $o C 4$ & $\mathrm{Cmcm}$ & $A 20$ & $\alpha \mathrm{U}$ \\
\hline
\end{tabular}

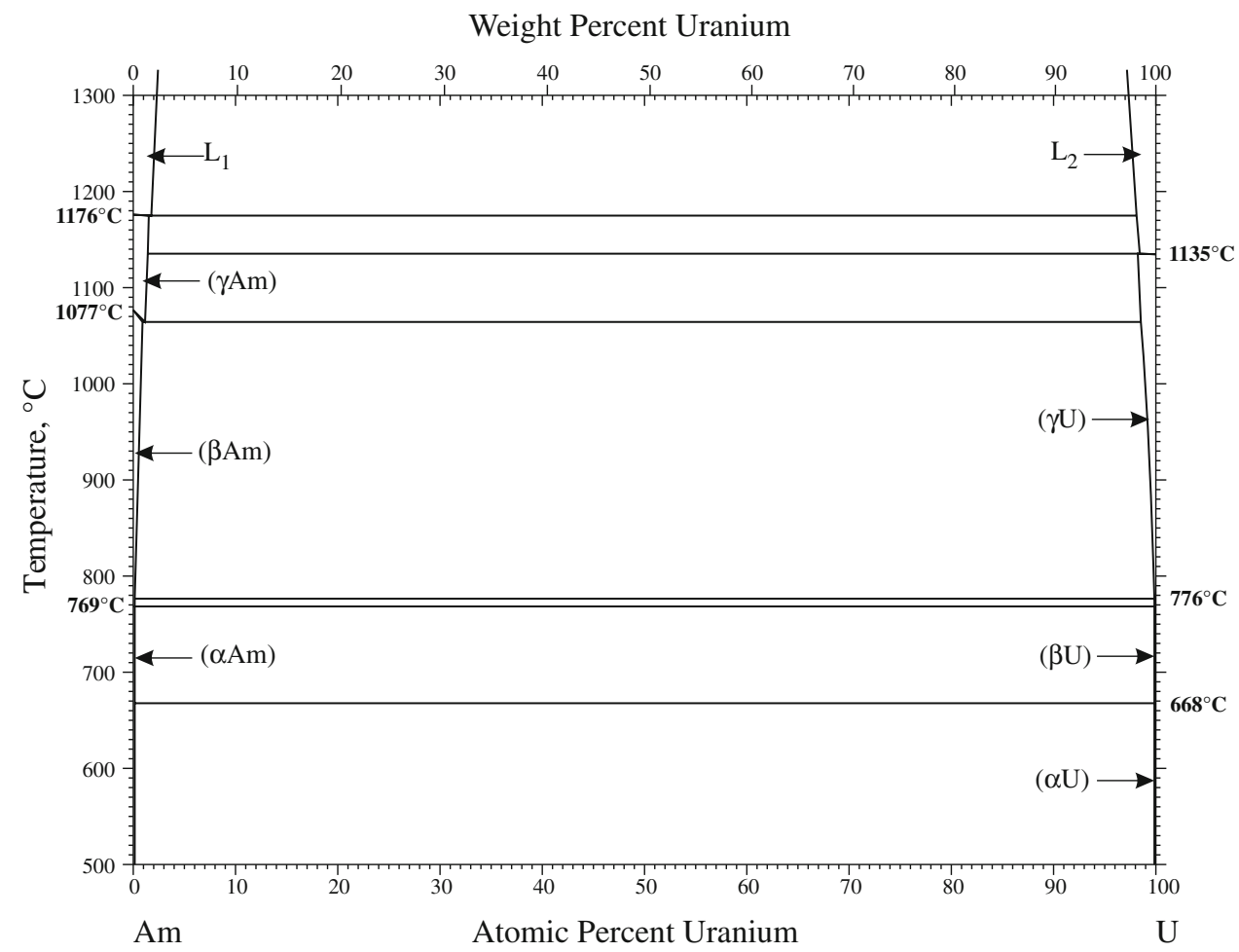

Fig. 1 Am-U phase diagram [2010Kur] 